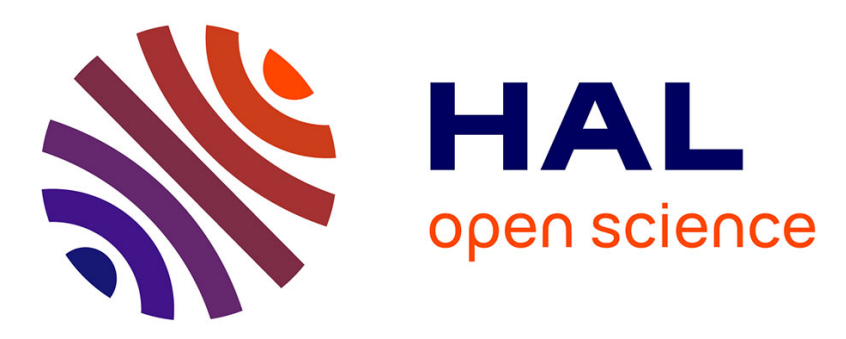

\title{
Modelling of multiple-mechanism agglomeration in a crystallization process
}

René David, Am Paulaime, Fabienne Espitalier, Loic Rouleau

\section{To cite this version:}

René David, Am Paulaime, Fabienne Espitalier, Loic Rouleau. Modelling of multiple-mechanism agglomeration in a crystallization process. Powder Technology, 2003, 130 (1-3, SI), pp.338-344. 10.1016/S0032-5910(02)00213-9 . hal-01678812

\section{HAL Id: hal-01678812 \\ https://hal.science/hal-01678812}

Submitted on 5 Sep 2018

HAL is a multi-disciplinary open access archive for the deposit and dissemination of scientific research documents, whether they are published or not. The documents may come from teaching and research institutions in France or abroad, or from public or private research centers.
L'archive ouverte pluridisciplinaire HAL, est destinée au dépôt et à la diffusion de documents scientifiques de niveau recherche, publiés ou non, émanant des établissements d'enseignement et de recherche français ou étrangers, des laboratoires publics ou privés. 


\title{
Modelling of multiple-mechanism agglomeration in a crystallization process
}

\author{
René David $^{\mathrm{a}, *}$, Anne-Margot Paulaime ${ }^{\mathrm{a}, \mathrm{b}}$, Fabienne Espitalier ${ }^{\mathrm{a}}$, Loic Rouleau ${ }^{\mathrm{b}}$ \\ ${ }^{a} L G P S D$, CNRS, Ecole des Mines d'Albi Carmaux, F-81013 Albi Cedex 09, France \\ ${ }^{b}$ IFP-CEDI, BP3, F-69390 Vernaison, France
}

\begin{abstract}
A three-level agglomeration model coupled with crystal growth is developed. It accounts for Brownian, laminar, and turbulent agglomeration. The desupersaturation profiles, the particle size distributions, the average sizes, and variances (or standard deviations), as well as the instantaneous agglomeration degrees for each mechanism, can be calculated as functions of time. The model is applied to the crystallization of an amorphous solid into a crystalline polymorph in a batch crystallizer. A runaway phenomenon is detected for agglomeration when crystals are switching over from the Brownian regime to the laminar one: this switchover significantly affects the desupersaturation curve and the crystal shapes.
\end{abstract}

Keywords: Crystallization; Agglomeration; Brownian; Laminar; Turbulent

\section{Introduction}

In many crystallization cases, the final structure of crystals shows multiple agglomeration levels with elementary crystals combined into primary agglomerates, which are themselves bound into secondary agglomerates of different sizes. A certain degree of agglomeration depending on operating conditions is required for the further use of the crystallized solid.

Agglomeration itself results from two steps, (a) binary collision of mother particles and (b) sticking by growth of crystalline bridges between particles [1]. Several authors [2-4] have evidenced the multiplicity of collision mechanisms and the existence of an efficiency factor for sticking, which is a function of (a) the size domains of mother particles and the agglomerate and (b) the hydrodynamic conditions. As far as the collision mechanism itself is concerned, one may distinguish Brownian (also sometimes called perikinetic), laminar (orthokinetic), and turbulent collision [2]. Similarly, the sticking efficiency depends on sizes $S_{j}$ and $S_{i}$ of mother particles.

\footnotetext{
* Corresponding author. Centre Poudres et Procédés, Ecole des Mines d'Albi Carmaux, F-81013 Albi Cedex 09, France. Fax: +33-563-49-3025.

E-mail address: rdavid@enstimac.fr (R. David).
}

Agglomeration rate constants have the following expressions (1-3) [2,3]; it is generally accepted that the agglomeration rate is proportional to the growth rate $G[3,4]$, but this point will be discussed later:

1. Brownian collision at small scales with efficiency proportional to $G[2]$ :

$\beta_{j, i, \mathrm{~b}}=k_{\mathrm{Ab}} G \frac{\left(S_{j}+S_{i}\right)^{2}}{S_{j} S_{i}}$

The transition scale from Brownian to laminar agglomeration can be related to the Batchelor microscale [5]. As a slab of suspension is stretched by the stirring power, it reduces from the Kolmogorov microscale $l_{\mathrm{K}}$ to the Batchelor microscale $l_{\mathrm{B}}$, where its shrinkage in thickness is compensated by diffusion of the very small Brownian agglomerates. The Brownian diffusion coefficient $D$ of these agglomerates of size $S_{i}$ writes after the classical Stokes-Einstein relation [6]

$D=k_{\mathrm{B}} T /\left(3 \pi \mu S_{i}\right)$

Using the classical expression [5] of Batchelor microscale,

$l_{\mathrm{B}}=\left(v D^{2} / P\right)^{1 / 4}$ 
If an agglomerate of size $S$ becomes larger than $l_{\mathrm{B}}$, it escapes from the suspension slab and is submitted to the laminar flow regime. Thus,

$l_{\mathrm{B}}=\left[\frac{k_{\mathrm{B}} T}{3 \pi \rho_{\text {susp }}}\right]^{1 / 3}\left[\frac{1}{P v}\right]^{1 / 6}$

2. Laminar collision for crystals smaller than the Kolmogorov microscale $l_{\mathrm{K}}=\left(v^{3} / P\right)^{1 / 4}$ with efficiency proportional to $G[3]$ :

$\beta_{j, i, 1}=k_{\mathrm{Al}} G\left(S_{j}+S_{i}\right)^{3}\left(\frac{P}{v}\right)^{1 / 2}$

Note that the laminar agglomeration rate constant is a third-power function of size, whereas the Brownian one is almost nonsensitive to the absolute size of mother particles. The transition from the Brownian mode to the laminar one will thus result in an acceleration of agglomeration.

3. Turbulent collision is assumed to take place between Kolmogorov and Taylor $\lambda_{\mathrm{c}}$ microscales. Sticking is then disturbed by turbulence $[1,3]$ :

$\lambda_{\mathrm{c}}=0.3 \Pi N D\left(\frac{60 v}{10 P}\right)^{1 / 2}$

$\left.\beta_{j, i, \mathrm{t}}=k_{\mathrm{At}} G \frac{\left(S_{j}+S_{i}\right)^{2}}{S_{j}} f\left(\frac{S_{i}}{S_{j}}\right) N D \quad 1-\frac{\left(S_{j}+S_{i}\right)^{2}}{\lambda_{\mathrm{c}}^{2}}\right)$

When the size of agglomerates approaches the Taylor scale $\lambda_{c}$, the above expression (7) shows that the agglomeration rate reduces to zero [1]. Then, the largest agglomerates are rapidly destroyed by the turbulence.

The turbulent agglomeration mode is less sensitive to the absolute size than is the laminar mode, but both rates are dependent on the stirring power $P$, whereas the Brownian agglomeration rate is not. Further, the increasing stirring power accelerates laminar and turbulent collisions.

Several models of crystallization (for instance, Refs. [1,4,7-9]) involve agglomeration processes. However, either constant agglomeration kernels are chosen [7] or a single collision mechanism is taken into account $[1,4,8,9]$. The aim of the present paper is to propose a model for cases where different types of agglomeration take place and are shown by the morphology of crystal agglomerates.

\section{Model}

The modelling of these processes is based on the method of classes, introduced by David et al. [1], where the size scale of particles is divided into $N_{\mathrm{c}}$ classes, whose limits are in geometric progression with a factor $2^{1 / 3}[10]$, i.e., a factor 2 for the volumes. $N_{\mathrm{c}}$ is chosen in order to verify $L_{N_{\mathrm{c}}}>\lambda_{\mathrm{c}}$. The impact on class $n$ of agglomerations between particles of classes $j$ and $i \geq j$ is represented by stoichiometric coefficients $v_{n, j, i}$ by analogy with a chemical reaction system. These coefficients have been calculated to conserve the solid volume balance and the disappearance of one single particle for each agglomeration (except for agglomeration $(i, i)$ where only half of the particle disappears due to symmetry).

Three different schemes of agglomeration have to be distinguished:

$$
\begin{aligned}
& 1 / 2(i)+1 / 2(i) \rightarrow 1 / 2(i+1) \\
& (i-1)+1 / 2(i) \rightarrow 1 / 2(i+1) \\
& V_{i} /\left(V_{i}-V_{j}\right)(j<i-1)+(i) \rightarrow V_{i} /\left(V_{i}-V_{j}\right)(i)
\end{aligned}
$$

The corresponding stoichiometric coefficients standing for the impact of agglomeration $(i, j)$ on class $n$ of particles are

$v_{n, i, i}=\delta_{n, i+1} / 2-\delta_{n, i}$

$v_{n, i-1, i}=\delta_{n, i+1} / 2-\delta_{n, i} / 2-\delta_{n, i-1}$

$v_{n, j, i}=V_{j} /\left(V_{i}-V_{j}\right) \delta_{n, i}-V_{i} /\left(V_{i}-V_{j}\right) \delta_{n, j}$

In other words, this description is now entirely consistent with the classical zeroth- and third-moment equations derived from the population balance equation in the case of agglomeration, whereas the former model of David et al. [1], resulted in an approximation of the zeroth moment equation.

The population balance is discretized into $N_{\mathrm{c}}$ classes. $\Psi$ represents the particle size density function. For $N_{\mathrm{c}}>n>1$ in a batch crystallizer with suspension volume $V_{\text {susp: }}$ :

$$
\begin{aligned}
\frac{1}{V_{\text {susp }}} \frac{\mathrm{d}\left(N_{n} V_{\text {susp }}\right)}{\mathrm{d} t}= & G\left(L_{n-1}\right) \Psi\left(L_{n-1}\right)-G\left(L_{n}\right) \Psi\left(L_{n}\right) \\
& +\sum_{k=\mathrm{b} ; \mathrm{l} ; \mathrm{t}} R_{\mathrm{A}, k, n}
\end{aligned}
$$

with $\Psi\left(L_{0}\right)=\Psi\left(L_{N_{\mathrm{c}}}\right)=0$. The resulting agglomeration rate for class $n$ is

$R_{\mathrm{A}, k, n}=\sum_{i=1}^{N_{\mathrm{c}}} \sum_{j=1}^{i} v_{n, j, i} \beta_{j, i, k} N_{j} N_{i}$

The total number of particles per suspension volume unit, which disappeared by agglomeration through mechanism $k$, is

$$
R_{\mathrm{A}, k, T}=\sum_{n=1}^{N_{\mathrm{c}}} R_{\mathrm{A}, k, n}
$$

Other equations account for the rate of production of solid mass [11], the macroscopic balance on the solute, the liquid phase volume, and the growth rate as a function of supersaturation. 
The different relevant mechanisms for the various types of collisions are given in Fig. 1. Agglomeration by laminar collision is much faster than agglomeration by Brownian collision above a size corresponding to the upper limit of class $m$. Turbulent collision takes place as soon as the size of a particle becomes larger than the Kolmogorov microscale in the suspension, i.e., above the upper limit of class $l$. Hence, the parameter number is reduced by assuming that the marginal rates of agglomeration are equal two by two for the particle sizes corresponding to the switching from one mechanism to the other.

Wachi and Jones [12], Puel [13], and Ilievski and Hounslow [14] have introduced two-property distribution functions for crystallization. Except for simple cases, it is generally expensive in terms of computing time when agglomeration is involved. However, the most interesting results of these models are the mean degrees of agglomeration, which can easily be compared to experimental results. Three average agglomeration degrees are defined as the average number of elementary structures (crystallites, primary agglomerates, and secondary agglomerates) contained in agglomerates (primary, secondary, and tertiary, respectively). They are based on the total number of particles, which disappeared as a consequence of the corresponding agglomeration mechanism.

With only one mechanism and starting from particle concentration $N_{0}$, the agglomeration degree would be

$$
\overline{n_{1}}(t)=\frac{1}{1+\int_{0}^{t} \frac{R_{\mathrm{A}, 1, T}}{N_{0}} \mathrm{~d} t}
$$

With two parallel mechanisms of agglomeration with respective global rates $R_{\mathrm{A}, 1, T}$ and $R_{\mathrm{A}, 2, T}$, the average number

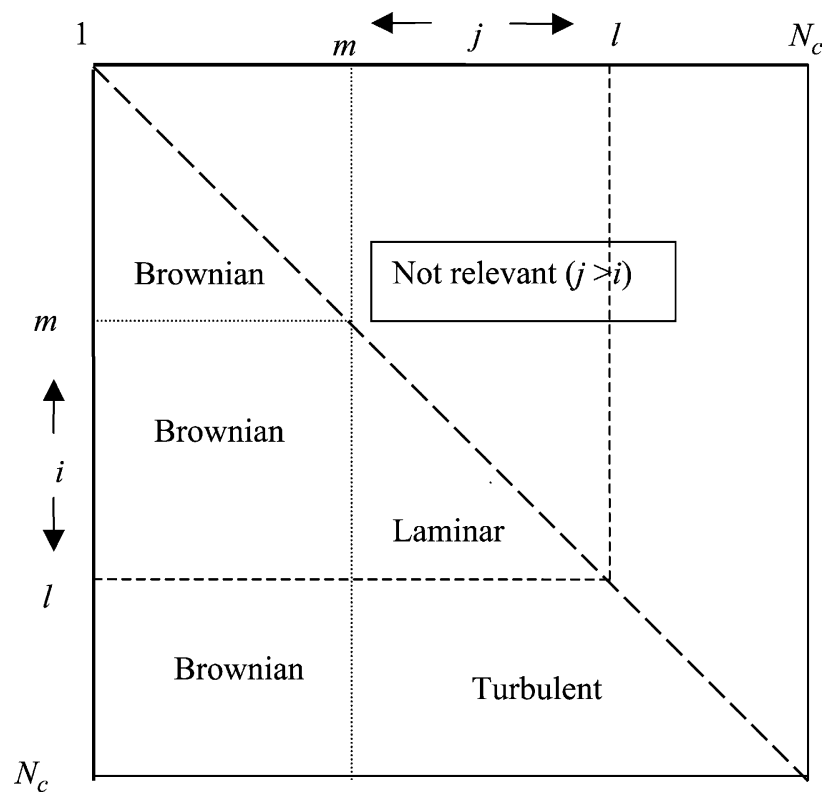

Fig. 1. Different types of agglomerations as functions of sizes (class numbers) of mother particles $(i, j<i)$. of primary agglomerates contained in secondary agglomerate writes

$$
\overline{n_{2}}(t)=\frac{1}{\overline{n_{1}}\left(1+\int_{0}^{t} \frac{\left(R_{\mathrm{A}, 1, T}+R_{\mathrm{A}, 2, T}\right)}{N_{0}} \mathrm{~d} t\right)}
$$

and so on.

$$
\overline{n_{3}}(t)=\frac{1}{\overline{n_{1}} \overline{n_{2}}\left(1+\int_{0}^{t} \frac{\left(R_{\mathrm{A}, 1, T}+R_{\mathrm{A}, 2, T}+R_{\mathrm{A}, 3, T}\right)}{N_{0}} \mathrm{~d} t\right)}
$$

The key point is that these parameters can be calculated from a single-property (i.e., particle size) distribution function.

\section{Application to the crystallization from an amorphous compound}

The model is applied to the crystallization of zeolites. In this type of crystallization, an amorphous gel is formed immediately after mixing the reactants $[15,16]$. This gel is poured into a batch crystallizer and heated at temperatures ranging between 80 and $250{ }^{\circ} \mathrm{C}$ where the amorphous solid transforms into a less soluble, crystalline solid. The following assumptions are made:

(a) The crystallizer is mechanically stirred (axial stirrer with a power number of 1 and diameter $D_{3}=0.1 \mathrm{~m}$ ). The suspension behaves from a rheological point of view like a Newtonian fluid with a kinematic viscosity close to $10^{-6} \mathrm{~m}^{2} \mathrm{~s}^{-1}$ at the temperature of crystallization.

(b) Amorphous particles with concentration $N_{0}$ and initial size $L_{0}=30 \mathrm{~nm}\left(S_{0}=27 \mathrm{~nm}\right)$ undergo nucleation and increase their size via growth and agglomeration. According to the literature [17], it is likely that the crystallite nucleation occurs on the surface of the existing amorphous phase, without any new primary nucleation in the solution.

(c) The initial supersaturation in the liquid phase is $\sigma_{0}$ with respect to the crystalline phase.

(d) The suspension volume of $10^{-2} \mathrm{~m}^{3}$ is constant.

(e) The increase of the solid mass during the whole process can be neglected.

(f) Dissolution of the amorphous compound is fast with respect to crystalline growth and agglomeration.

(g) The crystal growth is independent of crystal size. Its order is $k_{1}=1$ with respect to supersaturation.

(h) Agglomeration exists with the three mechanisms described above (Eqs. (1)-(7)). At temperatures around $200{ }^{\circ} \mathrm{C}$, a stirring speed of $5 \mathrm{~s}^{-1}$, a suspension density of about $10^{3} \mathrm{~kg} \mathrm{~m}^{-3}$, and a kinematic viscosity of about $10^{-6} \mathrm{~m}^{2} \mathrm{~s}^{-1}$, Eq. (4) yields $l_{\mathrm{B}}=150 \mathrm{~nm}$. This value is smaller than the upper limit postulated above for the primary agglomerates. The laminar- 


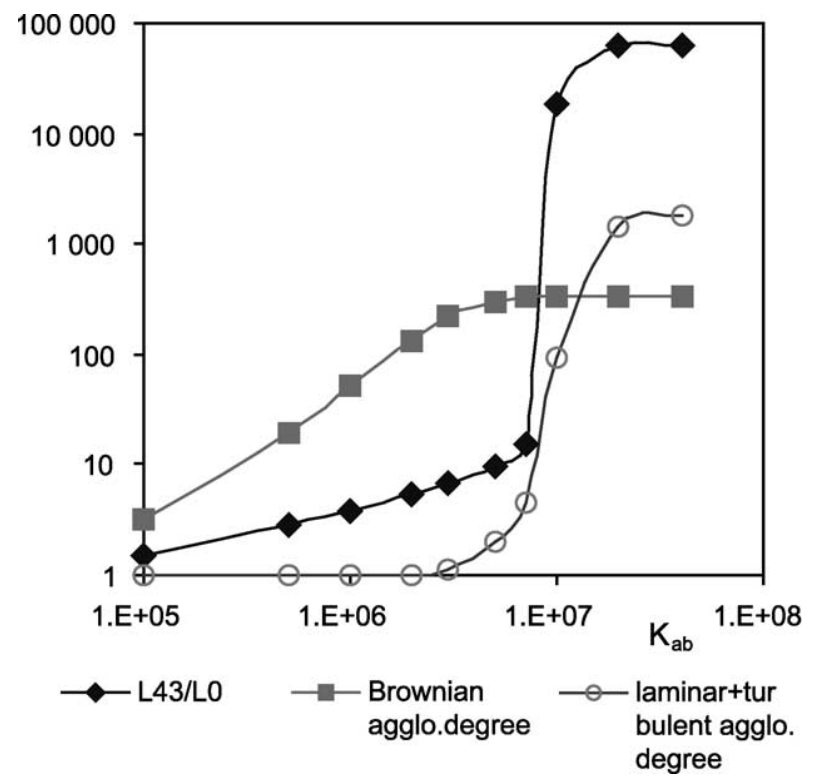

Fig. 2. Influence of the reduced Brownian agglomeration rate constant on reduced final average size and degrees of agglomeration $\left(c^{*}=10^{-6}\right.$, $\left.m_{0}=0.033, \sigma_{0}=10, N=5 \mathrm{~s}^{-1}\right)$.

turbulent transition occurs at about 50-30 $\mu \mathrm{m}$ (Kolmogorov microscale) and agglomeration stops at 3.5-2.5 mm (Taylor microscale) depending on stirring speed $\left(N=5-10 \mathrm{~s}^{-1}\right)$.

The above equation system is expressed in dimensionless variables: time $\theta=t G_{0} / L_{0}$ with $G=G_{0} \sigma^{k_{1}}$, size $\lambda=L / L_{0}$, average size $s=S / L_{0}$, crystal concentration $y_{n}=N_{n} / N_{0}$, CSD $\Phi=\Psi L_{0} / N_{0}$, concentration in the liquid phase $x_{1}=C_{1} /$ $C^{*}$, supersaturation $\sigma=C_{1} / C^{*}-1$, and concentration of the solid phase $x_{\mathrm{s}}=C_{\mathrm{s}} / C^{*}$.

The population balance writes for $N_{\mathrm{c}}>n>1$

$\frac{\mathrm{d} y_{n}}{\mathrm{~d} \theta}=\sigma^{k_{1}}\left(\Phi\left(\lambda_{n-1}\right)-\Phi\left(\lambda_{n}\right)\right)+\sum_{k=\mathrm{b}, 1, \mathrm{t}} \sum_{i=1}^{N_{c}} \sum_{j=1}^{i} v_{j, i, n} B_{j, i, k} y_{j} y_{i}$

The solid mass balance [6] is

$\frac{\mathrm{d} x_{\mathrm{s}}}{\mathrm{d} \theta}=\frac{3 m_{0}}{c^{*}}\left(\frac{\lambda_{0}}{S_{0}}\right)^{3} \sigma^{k_{1}} \sum_{n=1}^{N_{\mathrm{c}}} S_{n}^{2} y_{n}$

The solute + solid mass balance is

$x_{1}=x_{10}+\left(x_{s 0}-x_{s}\right) /\left(1-x_{s} c^{*}\right)$

Four reduced parameters remain: initial fraction of solid phase $m_{0}=m_{\text {tot }} /\left(\rho_{\mathrm{s}} V_{\text {susp }}\right)=\Phi_{v} \mathrm{~S}_{0}^{3} N_{0}$, initial supersaturation $\sigma_{0}=x_{10}-1$, the solubility $c^{*}=M_{\mathrm{s}} C^{*} / \rho_{\mathrm{s}}$, and the Brownian agglomeration rate constant $K_{\mathrm{Ab}}=L_{0} N_{0} k_{\mathrm{Ab}}$ (i.e., $B_{j, i, k}=\beta_{j, i, k} L_{0} N_{0} / G_{0}$ ).
The initial conditions of the above equations are

$y_{1}=1 ; y_{n}=0 ; x_{s}=x_{s 0}=m_{0} /\left(s_{0}^{3} c^{*}\right)$

\section{Results and discussion}

The integration of the equation system (Eqs. (16)-(19)) is made by an upstream differentiation method D02EAF of the NAG library. Supersaturation, average reduced sizes (in number and mass), reduced variances, crystal concentration per class, and average agglomeration degrees are calculated against time.

As it is difficult to check experimentally if an agglomerate has been produced under laminar or turbulent conditions, an overall laminar + turbulent degree of agglomeration is defined.

$\bar{n}_{1+\mathrm{t}}=\bar{n}_{1} \bar{n}_{\mathrm{t}}$

Figs. 2-4 show the final average mass size and the Brownian and laminar + turbulent agglomeration degrees as functions of the dimensionless parameters.

When $\bar{n}_{1+\mathrm{t}}=1$, Brownian agglomeration is the main agglomeration mode. The increase of the Brownian agglomeration constant $K_{\mathrm{Ab}}$ (Fig. 2) causes the start-up of the laminar agglomeration mode because of the higher sizes attained. The average mass size and the agglomeration degree suddenly increase while the Brownian agglomeration

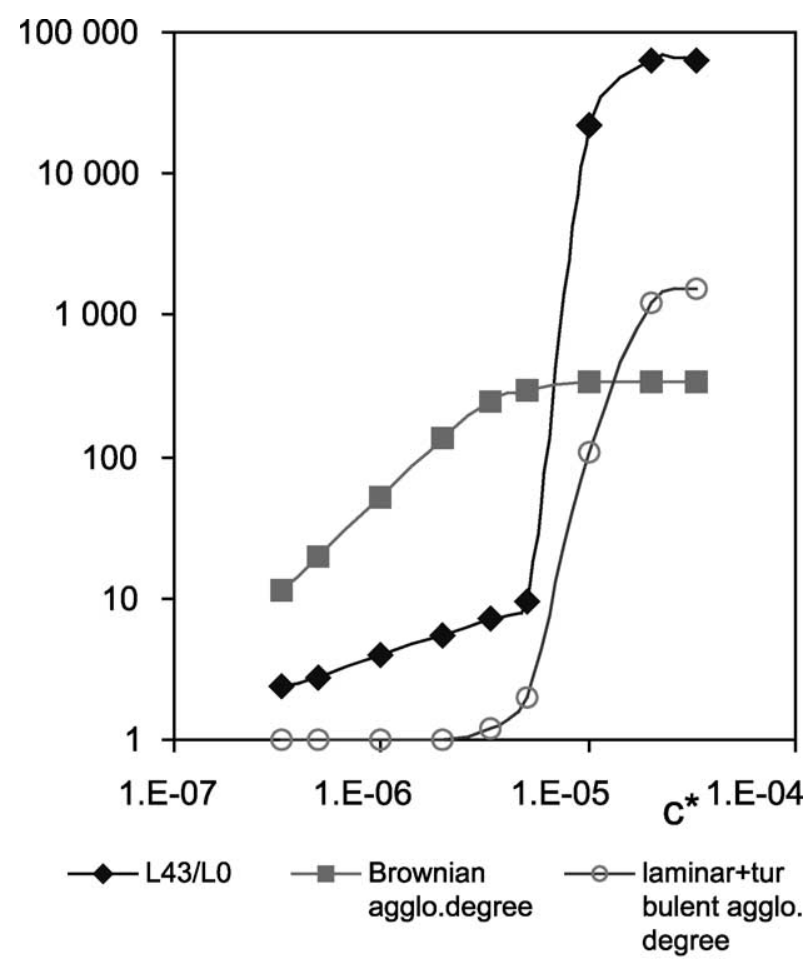

Fig. 3. Influence of reduced solubility $c^{*}$ on the reduced final average size and degrees of agglomeration $\left(K_{\mathrm{Ab}}=10^{6}, m_{0}=0.033, \sigma_{0}=10, N=5 \mathrm{~s}^{-1}\right)$. 


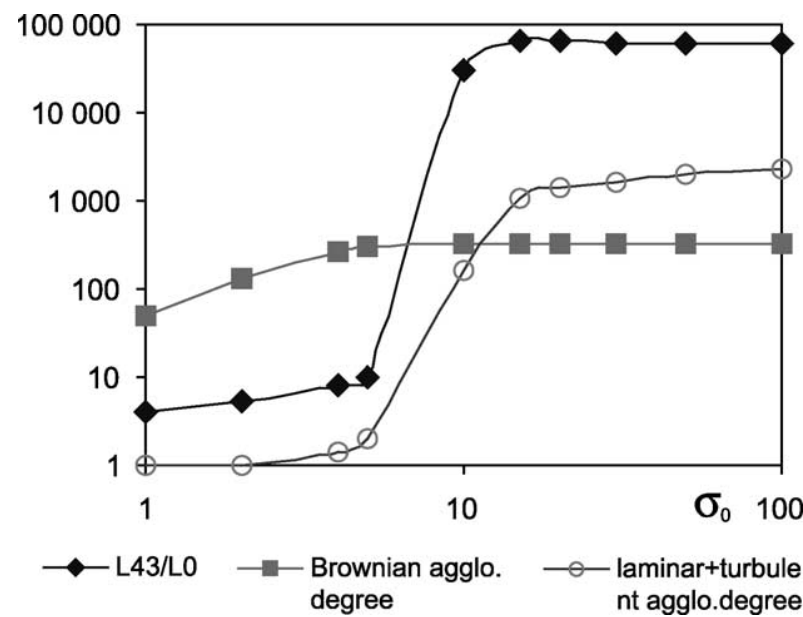

Fig. 4. Influence of initial supersaturation on the final reduced average size and degrees of agglomeration $\left(K_{\mathrm{Ab}}=10^{6}, c^{*}=10^{-6}, m_{0}=0.033, N=5\right.$ $\left.\mathrm{s}^{-1}\right)$.

degree stays constant as a consequence of the constant Brownian-laminar transition size. The same effect is obtained for the increase of dimensionless solubility $c^{*}$ (Fig. 3), which enhances growth and thus agglomeration rates through increased initial solute concentration at constant $\sigma_{0}$. In turn, the decrease of $\sigma_{0}$ at constant $c^{*}$ results in lower supersaturations and thus in smaller growth and agglomeration rates (Fig. 4). There is no significant influence of $m_{0}$ (not reported).

Fig. 5 shows typical desupersaturation profiles for different sets of parameter values. When compared with Figs. 2 and 3 , it can be seen that the shapes of the curves are clearly modified when a significant laminar + turbulent agglomeration occurs. As long as the Brownian agglomeration is the dominant mode, the curves are simply shifted to the right side (higher reduced times) while the final agglomerate size and Brownian agglomeration degree both increase: The increased agglomeration reduces the surface available for growth and the desupersaturation proceeds more slowly. Doubling the stirring speed $N$ during the crystallization, i.e., multiplying the dissipated power by a factor 8 has then almost no effect (see Figs. 5 and 6).

If other types of agglomeration are significant (for instance, higher values of $K_{\mathrm{Ab}}$ ), the desupersaturation rate is further reduced (Fig. 5). Since the agglomeration is enhanced by higher stirring speeds, the desupersaturation proceeds at a slower rate for $N=10 \mathrm{~s}^{-1}$ than for $N=5 \mathrm{~s}^{-1}$ (Fig. 5), but the agglomeration degrees and the average final crystal sizes are higher. However, the maximum size of crystals is smaller at the higher stirring speed as a consequence of Eq. (6). As a result, the CSD is narrower for $N=10 \mathrm{~s}^{-1}$ than for $N=5 \mathrm{~s}^{-1}$ (Fig. 6).

Whereas small agglomerates (less than $1 \mu \mathrm{m}$ ) are made from elementary crystallites (see Figs. 2 and 6), which have limited growth because all the supersaturation is consumed at $\theta \leq 10^{-2}$ (Fig. 5), larger agglomerates show a quite different aspect. Their macrostructure is of the order of magnitude of $1 \mathrm{~mm}$ in size (Fig. 6) and encompasses up to some thousands of primary agglomerates (Fig. 2). If one looks at the micrometric scale, primary agglomerates are made out of a quasi-constant number of crystallites, which stay very close to their initial size (Fig. 2).

This model can be improved on different points.

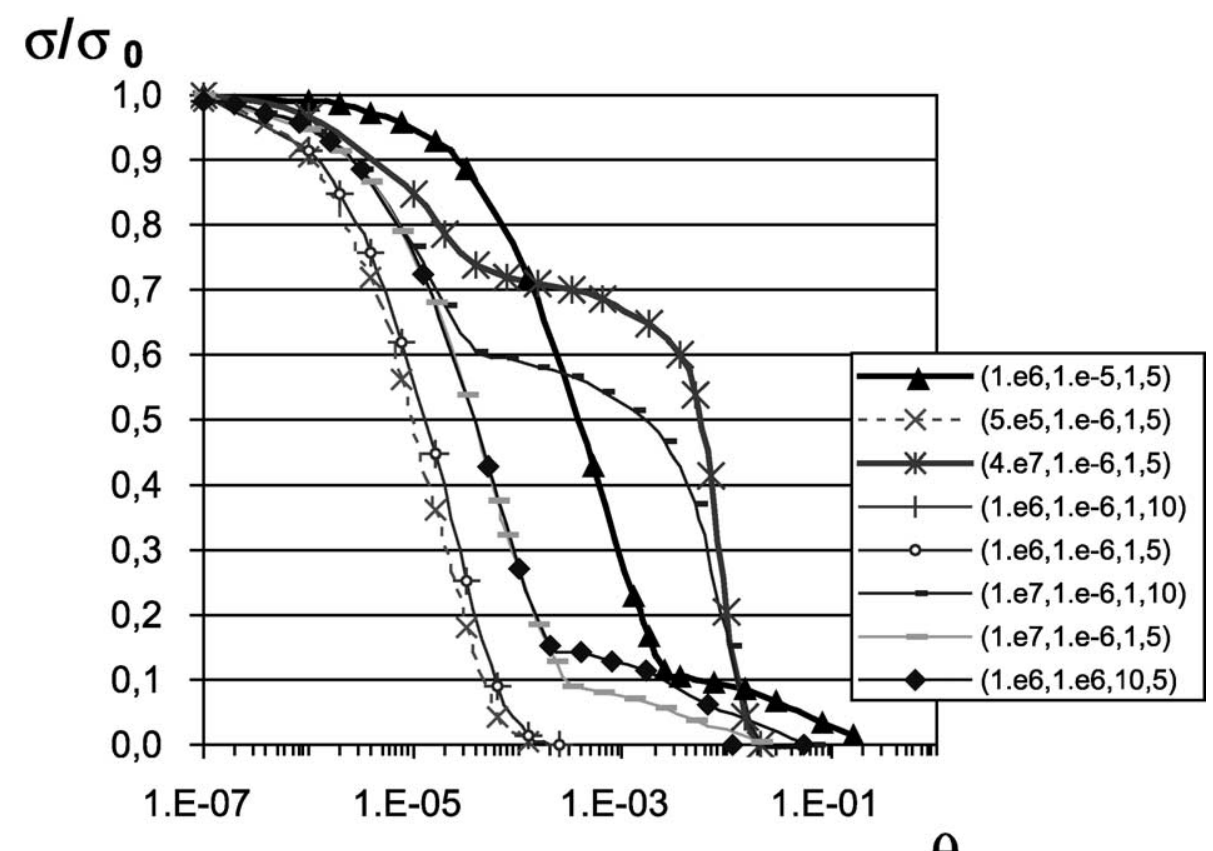

Fig. 5. Influence of parameter values $\left(K_{\mathrm{Ab}}, c^{*}, \sigma_{0}, N\left(\mathrm{~s}^{-1}\right)\right),\left(m_{0}=0.033\right)$ on the desupersaturation curve $\sigma / \sigma_{0}$ against time. 


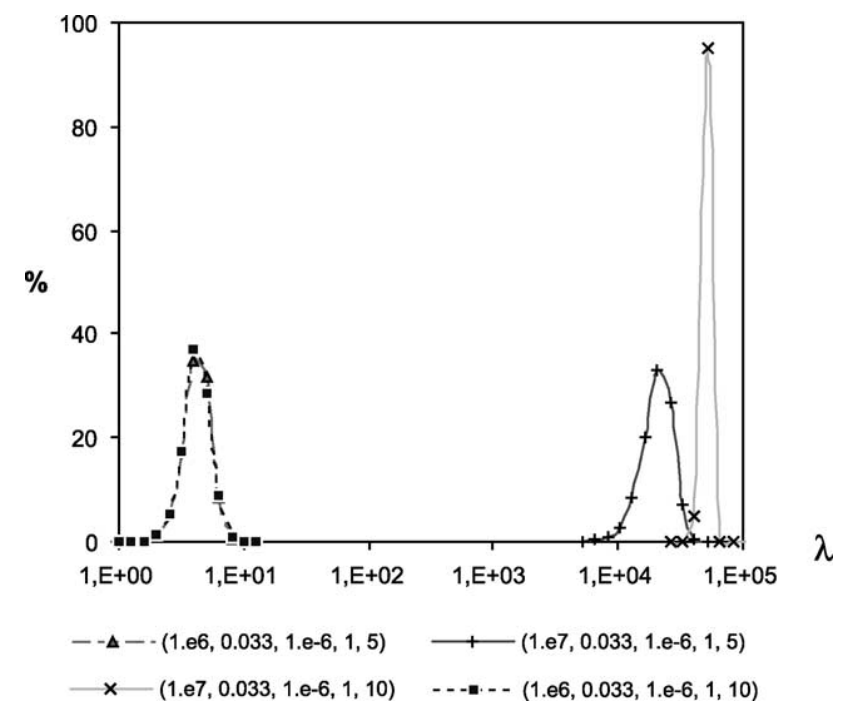

Fig. 6. Influence of parameter values $\left(K_{\mathrm{Ab}}, m_{0}, c^{*}, \sigma_{0}, N\left(\mathrm{~s}^{-1}\right)\right)$ on the final CSD in mass fractions.

The first comment addresses the expressions of the agglomeration rate constant (Eqs. (1) and (2)) for the Brownian and laminar regimes.

In the Brownian regime, for spherical particles agglomerates [16]

$\beta_{j, i, \mathrm{~b}}=\frac{2 k_{\mathrm{B}} T \eta}{3 \mu} \frac{\left(S_{j}+S_{i}\right)^{2}}{S_{j} S_{i}}$

From the comparison of relations (1) and (21), it is obvious that the efficiency $\eta$ of collisions is assumed to be proportional to the growth rate $G$. However, this is an approximation, which holds only for small growth rates (as usual for zeolites [17]), since $\eta$ must lie between 0 and 1 . The same comment applies to laminar agglomeration. More sophisticated expressions for $\eta$ like that introduced by Hounslow et al. [4] will probably be closer to the physical reality.

For turbulent agglomeration, the expression of efficiency proposed by David et al. [1], is included in Eqs. (6) and (7).

An additional comment concerns the upper size of the Brownian range $l_{\mathrm{B}}$ : Our experimental observations on zeolites suggest a higher value than $150 \mathrm{~nm}$ for $l_{\mathrm{B}}$, i.e., between 500 and $1000 \mathrm{~nm}$. Thus, the Brownian regime may be extended to sizes higher than $l_{\mathrm{B}}$.

Finally, the internal porosity of agglomerates should be considered in the model. In the case of zeolites, this porosity generally appears to be negligible for Brownian agglomerates in SEM pictures but it is significant for laminar or turbulent agglomeration.

\section{Conclusion}

Agglomeration, which takes place during crystallization of a finely divided amorphous compound into a crystalline species, has been simulated in a mechanically stirred tank via a model of size classes derived from the population balance. It takes into account three mechanisms of collision (Brownian, laminar, and turbulent) followed by sticking, which depends on the hydrodynamic conditions and the size of particles that collide. Agglomeration is accompanied by crystal growth. Different degrees of agglomeration have been defined for each mechanism. This model has been proven to perform well and it does not require too much computing capacity. Very different evolutions in terms of supersaturation profiles, average size, and size distributions as well as agglomerate shapes have been simulated, depending on agglomeration constants, solubility, initial supersaturation, and hydrodynamics, especially stirring speeds.

Several improvements can be achieved in the future, taking into account the comparison of the model with experimental results, and the efficiencies of collisions for agglomerations.

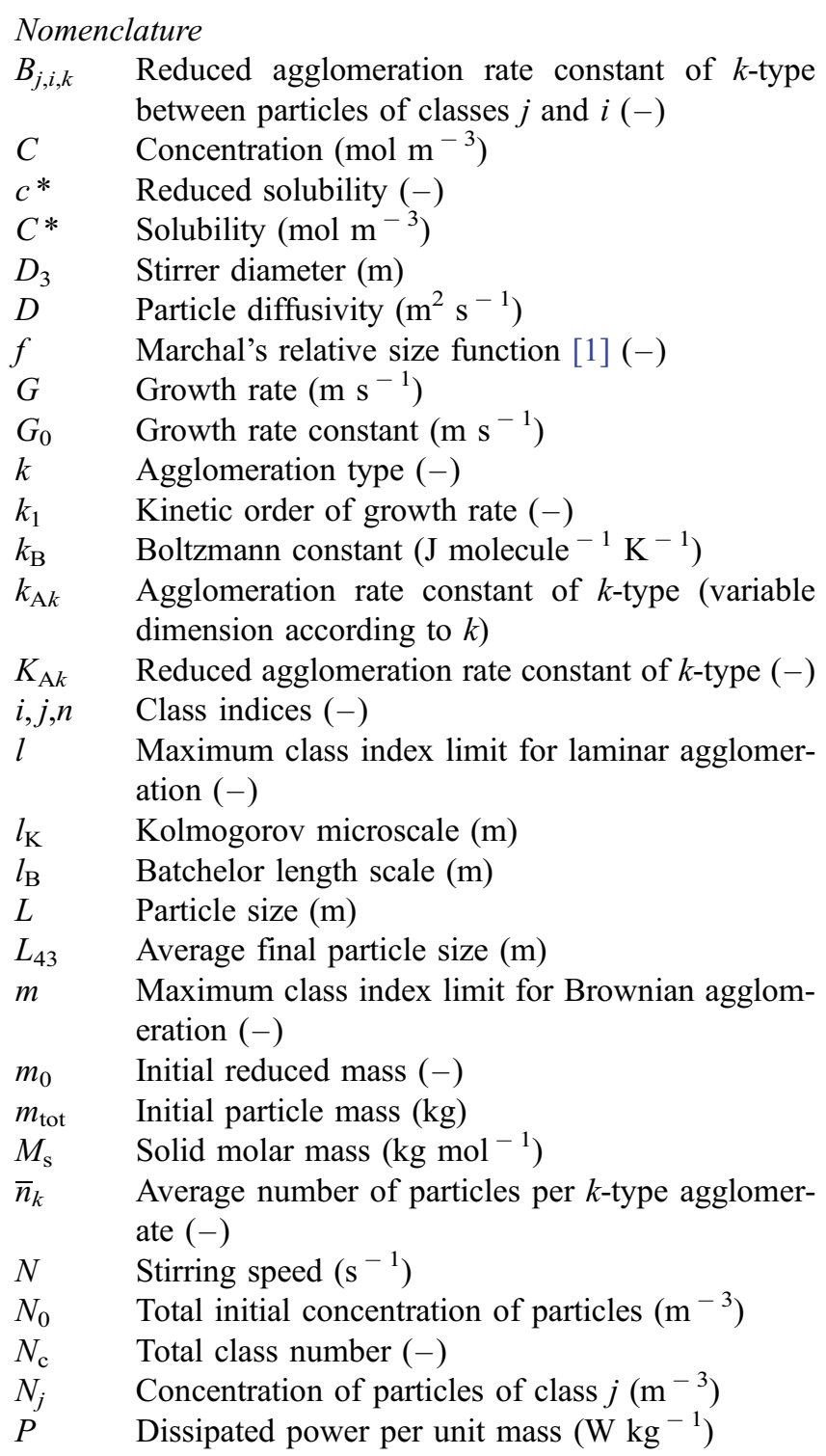


$R_{\mathrm{A}, k, n} \quad$ Agglomeration rate of class $n$ for agglomeration of type $k\left(\mathrm{~m}^{-3} \mathrm{~s}^{-1}\right)$

$R_{\mathrm{A}, k, T} \quad$ Global agglomeration rate for agglomeration of type $k\left(\mathrm{~m}^{-3} \mathrm{~s}^{-1}\right)$

$s \quad$ Reduced average size $(-)$

$S_{i} \quad$ Class average size $=\left(L_{i-1}+L_{i}\right) / 2(\mathrm{~m})$

$t \quad$ Time (s)

$T \quad$ Temperature (K)

$V_{i} \quad$ Average volume of crystal of class $i\left(\mathrm{~m}^{3}\right)$

$V_{\text {susp }} \quad$ Suspension volume (m)

$x \quad$ Reduced concentration in the suspension $(-)$

$y_{n} \quad$ Reduced particle concentration in class $n(-)$

$\beta_{j, i, k} \quad$ Agglomeration constant of $k$-type between particles of classes $j$ and $i\left(\mathrm{~m} \mathrm{~s}^{-1}\right)$

$\delta_{n, i} \quad$ Element of Kronecker matrix (-)

$\eta \quad$ Collision efficiency (-)

$\Phi \quad$ Reduced particle size density function (CSD) (-)

$\Phi_{v} \quad$ Volumetric shape factor (-)

$\lambda \quad$ Reduced particle size $\left(=L / L_{0}\right)(\mathrm{m})$

$\lambda_{\mathrm{c}} \quad$ Taylor microscale $(\mathrm{m})$

$\mu \quad$ Dynamic viscosity $\left(\mathrm{kg} \mathrm{m}^{-1} \mathrm{~s}^{-1}\right)$

$v \quad$ Kinematic viscosity $\left(\mathrm{m}^{2} \mathrm{~s}^{-1}\right)$

$v_{n, j, i} \quad$ Stoichiometric coefficient accounting for the impact of agglomeration $(j, i)$ on particle class $n$ $(-)$

$\rho_{\mathrm{s}} \quad$ Solid density $\left(\mathrm{kg} \mathrm{m}^{-3}\right)$

$\rho_{\text {susp }} \quad$ Suspension density $\left(\mathrm{kg} \mathrm{m}^{-3}\right)$

$\Psi \quad$ Particle size density function (CSD) $\left(\mathrm{m}^{-4}\right)$

$\sigma \quad$ Supersaturation (-)

$\theta \quad$ Reduced time $(-)$

Subscript 0 denotes initial conditions, subscript $l$ a liquid, subscript $s$ a solid.

\section{Acknowledgements}

The authors thank the Institut Français du Pétrole for scientific and financial support of this work.

\section{References}

[1] R. David, P. Marchal, J.P. Klein, J. Villermaux, Chem. Eng. Sci. 46 (1991) 205.

[2] A. Mersmann, in: A. Mersmann (Ed.), Crystallization Technology Handbook, Marcel Dekker, New York, 1994, p. 157.

[3] R. David, P. Marchal, B. Marcant, Chem. Eng. Technol. 18 (1995) 302.

[4] M.J. Hounslow, H.S. Mumtaz, A.P. Collier, J.P. Barrick, A.S. Bramley, Chem. Eng. Sci. 56 (1999) 2543.

[5] J. Baldyga, J. Bourne, Turbulent Mixing and Chemical Reactions, Wiley, Chichester, UK, 1999, p. 78.

[6] D. Everett, Basic Principles of Colloid Science, Royal Society of Chemistry, London, UK, 1988.

[7] A.S. Bramley, M.J. Hounslow, R.L. Ryall, J. Colloid. Interface Sci. 183 (1996) 155.

[8] L. Madec, L. Falk, E. Plasari, Chem. Eng. Sci. 56 (2001) 1731.

[9] M. Wulkow, A. Gerstlauer, U. Nieken, Chem. Eng. Sci. 56 (2001) 2575.

[10] M.J. Hounslow, R.L. Ryall, V.R. Marshall, AIChE J. 34 (1988) 1821.

[11] M. Aoun, E. Plasari, R. David, J. Villermaux, Chem. Eng. Sci. 54 (1999) 1161.

[12] S. Wachi, A.G. Jones, Chem. Eng. Sci. 54 (1992) 3145.

[13] F. Puel, PhD thesis, Université de Lyon I, France, 1994.

[14] D. Ilievski, M.J. Hounslow, AIChE J. 41 (1995) 525.

[15] D.W. Breck, Zeolite Molecular Sieves, Wiley-Interscience, New York, 1974, p. 245.

[16] R.M. Barrer, Hydrothermal Chemistry of Zeolites, Academic Press, London, UK, 1982, p. 105.

[17] J.H. Koegler, H. van Bekkum, J.C. Jansen, Zeolites 19 (1997) 262. 